\section{ON THE PRECESSIONAL MOTION OF A LIQUID ${ }^{1}$}

THE formulas expressing this mation were laid before the meeting and briefly explained, but the analytical treatment of them was reserved for a more mathematical paper to be communicated to the Section on Saturday. The chief object of the present communication was to illustrate experimentally a conclusion from this theory which had been announced by the author in his opening address to the Section, to the effect, that, if the period of the precession of an oblate spheroidal rigid shell full of liquid is a much greater multiple of the rotational period of the liquid than any diameter of the spheroid is of the difference between the greatest and least diameters, the precessional effect of a given couple acting on the shell is approximately the same as if the whoie were a solid rotating with the same rotational velocity. The experiment consisted in showing a liquid gyrostat, in which an oblate spheroid of thin sheet copper filled with water was substituted for the solid fly-wheel of the ordinary gyrostat. In the instrument actually exhibited, the equatorial diameter of the liquid shell exceeded the polar axis by about one-tenth of either.

Supposing the rotational speed to be thirty turns per second, the effect of any motive which, if acting on a rotating solid of the same mass and dimensions, would produce a precession having its period a considerable multiple of $\frac{1}{3}$ of a second, must, according to the theory, produce very approximately the same precession in the thin shell flled with liquid as in the rotating solid. Accordingly the main precessional phenomena of the liquid gyrostat were not noticeably different from those of ordinary solid gyrostats which were shown in action for the sake of comparison. It is probable that careful observation without measurement might show very sensible differences between the performances of the liquid and the solid gyrostat in the way of nutational tremors produced by striking the case of the instrument with the fist.

No attempt at measurement either of speeds or forces was included in the communication, and the author merely showed the liquid gyrostat as a rough general illustration, whici he hoped might be regarded as an interesting illustration of that very interesting result of mathematical hydro-kinetics the quasi-rigidity produced in a frictionless liquid by rotation.

P.S.-Since the communication of this paper to the Association, and the delivery of my opening address which preceded it on the same day, I have received from Prof. Henry No. 240 of the Smithsonian Contributions to Knowledge, of date October, 1871, entitled "Problems of Rotatory Motion presented by the Gyroscope, the Precession of the Equinoxes and the Pendulum," by Brevet Major-Gen. J. G. Barnard, Col. of Engineers, U.S.A., in which $I$ find a dissent, from the portion of my previouslypublished statements which I had taken the occasion of my address to correct, expressed in the following terms :-

"I do not concur with Sir William Thomson in the opinions quoted in note p. 38 , from Thomson and Tait, and expressed in his letter to Mr. G. Poulett Scrope (NATURE, Feb. I, 1872). So far as regards fluidity, or imperfect rigidity, within an infinitely rigid envelope, I do not think the rate of precession would be affected."

Elsewhere in the same paper Gen. Barnard speaks of "the practical rigidity conferred by rotation." Thus he has anticipated my correction of the statements contained in my paper on the Rigidity of the Earth, so far as regards the effect of interior fiuidity on the precessional motion of a perfectly rigid ellipsoidal shell filled with fluid.

I regret to see that the other error of that paper, which I corrected in my opening address, had not been corrected

x Communicated to Section A of the British Association, Thursday, September 7,2876 . by Gen. Barnard, and that the plausible reasoning which had led me to it had also seemed to him convincing. For myself, I can only say that I took the very earliest opportunity to correct the errors after I found them to be errors, and that I deeply regret any mischief they may have done in the meantime.

Addendum.-Solid and Liquid Gyrostats.-The solid gyrostat has been regularly shown for many years in the

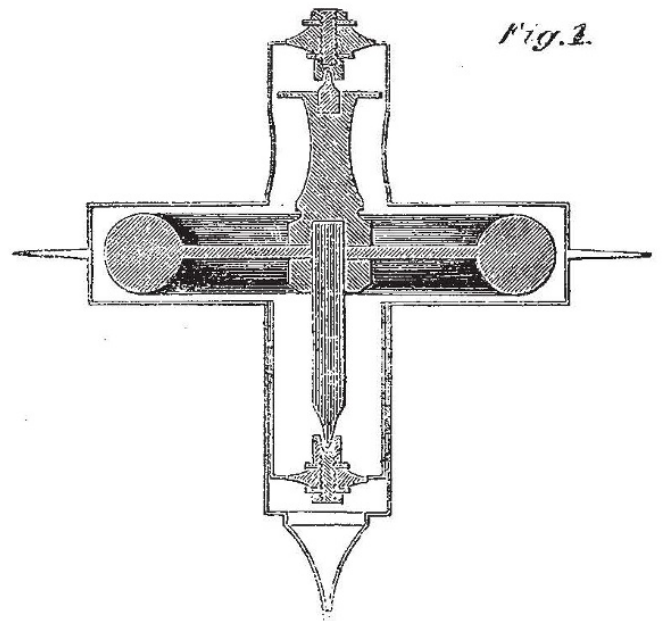

Natural Philosophy Class of the University of Glasgow as a mechanical illustration of the dynamics of rotating solids, and it has also been exhibited in London ard Edinburgh at conversaziones of the Royal Societies and of the Society of Telegraph Engineers, but no account of it has yet been published. The following brief description and drawing may therefore even now be acceptable to readers of NATURE :-

The solid gyrostat consists essentially of a massive flywheel possessing great moment of inertia, pivoted on the two ends of its axis in bearings attached to an outer case which completely incloses it. Fig. I zepresents a sectioa

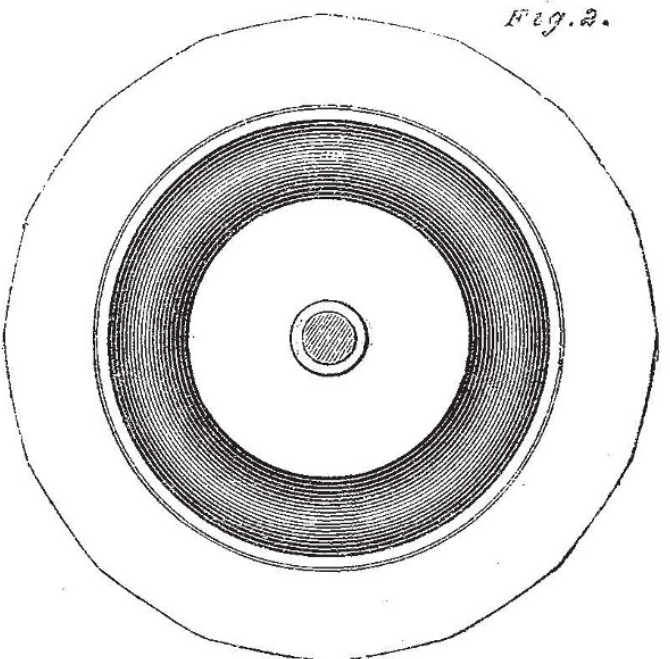

by a plane through the axis of the fly-wheel, and Fig. 2 a section by a plane at right-angles to the axis and cutting through the case just above the fiy-wheel. The containing case is fitted with a thin projecting edge in the plane of the fly-wheel, which is called the bearing edge. Its boundary forms a regular curvilinear polygon of sixteen sides with its centre at the centre of the fly-wheel. Each side of the polygon is a small arc of a circle of radius 
greater than the distance of the corners from the centre. The friction of the fly-wheel would, if the bearing-edge were circular, cause the case to roll along on it like a hoop, and it is to prevent this effect that the curved polygonal form described above and represented in the drawing is given to the bearing-edge.

To spin the solid gyrostat a piece of stout cord about forty feet long and a place where a clear run of about

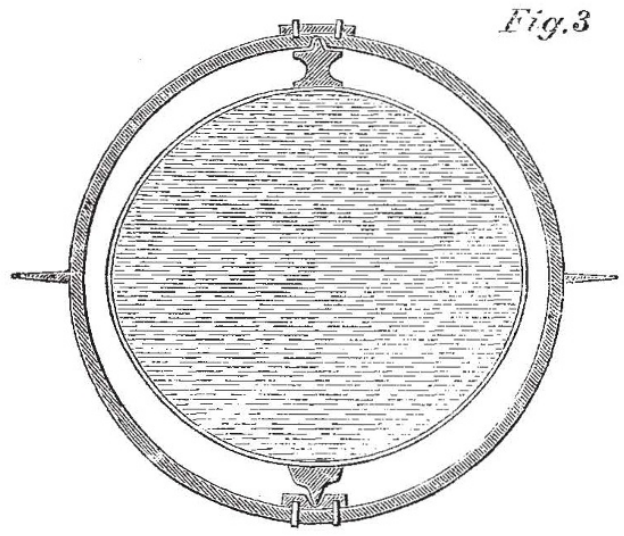

sixty feet can be obtained are convenient. The gyrostat having been placed with the axis of its fly-wheel vertical, the cord is passed in through an aperture in the case, twoand-a.half times round the bobbin-shaped part of the shaft, and out again at an aperture on the opposite side. Having taken care that the slack cord is placed clear of all obstacles and that it is free from kinks, the operator holds the gyrostat steady so that its case is prevented from turning, while an assistant pulls the cord through by running, at a gradually increasing pace, away from the instrument, while holding the end of the cord in his hand. Sufficient tension is applied to the entering cord to prevent it from slipping rourd on the shaft. In this way a very great angular

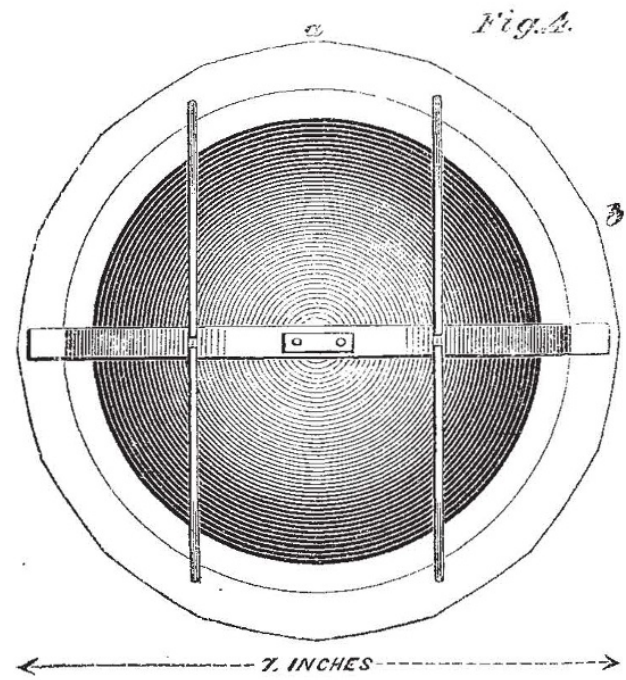

velocity is communicated to the fly-wheel, sufficient, indeed, to keep it spinning for upwards of twenty minutes.

If when the gyrostat has been spun it be set on its bearing edge with the centre of gravity exactly over the bearing point, on a smooth horizontal plane such as a piece of plate-glass lying on a table, it will continue apparently stationary and in stable equilibrium. If while it is in this position a couple round a horizontal axis in the plane of the fly-wheel be applied to the case, no deflection of this plane from the vertical is produced, but it rotates slowly round a vertical axis. If a heavy blow with the fist be given to the side of the case, it is met by what seems to the senses the resistance of a very stiff slastic body, and, for a few seconds after the blow, the gyrostat is in a state of violent tremor, which, however, subsides rapidly. As the rotational velocity gradually diminishes, the rapidity of the tremors produced by a blow also diminishes. It is very curious to notice the tottering condition, and slow, seemingly palsied, tremulousness of the gyrostat, when the fly-wheel has nearly ceased to spin.

In the liquid gyrostat the fly-wheel is replaced by an oblate spheroid, made of thin sheet copper, and filled with water. The ellipticity of this shell in the instrument exhibited is $\frac{1}{10}$, that is to say, the equatorial diameter exceeds the polar by that fraction of either. It is pivoted on the two ends of its polar axis in bearings fixed in a circular ring of brass surrounding the spheroid. This circle of brass is rigidly connerted with the curved polygonal-bearing edge which lies in the equatorial plane of the instrument, thus forming a frame-work for the support of the axis of the spheroidal shell. In Fig. 3 a section is represented through the axis to show the ellipticity, and Fig. 4 gives a view of the gyrostat as seen from a point in the prolongation of the axis. To prevent accident to the shell when the gyrostat falls down at the end of its spin, cage bars are fitted round it in such a way that no plane can touch the shell.

The method of spinning the liquid gyrostat is similar to that described for the solid gyrostat, differing only in the use of a very much longer cord and of a large wheel for the purpose of pulling it. The cord is first wound on a bobbin, free to rotate round a fixed pin. The end of it is then passed two-and-a-half times round the little pulley shown in the annexed sectional drawing, and thence to a point in the circumference of the large wheel to which it is fixed. An assistant then turns the wheel with gradually increasing velocity, while the frame of the gyrostat is firmly held, and the requisite tension applied to the entering cord to prevent it from slipping round the puliey.

WJLLiam THOMSON

\section{REMARKABLE PLANTS \\ I.-THE COMPASS-Plant.}

"Look at this delicate plant that lifts its head from the meadow, See how its leaves all point to the north, as true as the magnet It is the compass-plant that the finger of God has suspended Here on its fragile stalk, to direct the traveller's journey,
Over the sea-like, pathless, limitless waste of the desert LONGFELLOW'S Evangelite.

$\mathrm{T}^{\mathrm{T}}$ has long been known that there grows on the 1 prairie-lands of the south-western part of the United States of America, especially Texas and Oregon, a plant which has the peculiar property of turning its leaves towards the north, and which hence serves as a magnet to the traveller when no other means is available of ascertaining the points of the compass. It is probable, however, from Longfellow's description of it as a "delicate plant" on a "fragile stalk," that he never saw it growing. The Compass-plant is a member of the enormous natural order Compositæ, known to botanists as Silphium laciniatum. It is described as a stout perennial plant from three to six feet in height, with ovate, deeplypinnatifid leaves and large yellow heads of unisexual flowers, the ray-florets strap-shaped and female, the discflorets tubular and male. It is also known as the pilotweed, polar-plant, rosin-weed, and turpentine-weed, the two last names being derived from the abundant resin exuded by the stem; and is occasionally to be seen in English gardens.

The "polarity" of the leaves of this singular plant has long been familiar to hunters and other denizens of the prairie, who, "when lost on the prairies in dark nights, 